\title{
A EXPERIÊNCIA DO CINEMA COMO FERRAMENTA DA APRENDIZAGEM NA ESCOLA
}

\section{Alípio de Araújo Pereira ${ }^{1}$; Fernando Miranda da Silva²; Maria Cristina Cavalcanti Araújo ${ }^{3}$}

\section{Introdução}

O Programa Institucional de Bolsas de Iniciação à Docência (PIBID) oferece bolsas de iniciação à docência aos alunos de licenciaturas de cursos presenciais e a distância que se dediquem ao estágio nas escolas públicas e que, incentivo à docência, se comprometam com o exercício do magistério na rede pública

O projeto CineCal é uma das ações realizadas por estudantes bolsistas do PIBID na Escola Estadual Castro Alves, localizada no Bairro de Nova Descoberta, em Natal, no Rio Grande do Norte e tem o objetivo de, através da exibição e análise de filmes, correlacioná-los com os temas abordados pela disciplina de Geografia. O referido projeto é voltado aos alunos do ensino médio e busca promover e estimular a reflexão e consequentemente um maior aprendizado sobre os conteúdos trabalhados na disciplina de Geografia

A respeito da utilização do vídeo como ferramenta didática, Moran (1995), aponta que pode render bons resultados. Usando-o, ultrapassamos a barreira das aulas expositivas, gerando aulas mais dinâmicas e trazendo os alunos para o centro do processo de aprendizagem. Nesse sentido, no primeiro bimestre do ano de 2015, foi sugerido pelo professor Israel França (supervisor do PIBID) aos bolsistas do PIBID a exibição de um filme aos secundaristas do Castro Alves, foi pensada então a criação do Projeto CineCal.

É papel da geografia preparar o aluno para ter a capacidade de localizar, compreender e atuar no mundo complexo, e reconhecer as dinâmicas existentes no

\footnotetext{
1 Geografia, Instituto Federal de Educação, Ciência e Tecnologia Rio Grande do Norte, alipio.apereira@gmail.com

2 Geografia, Instituto Federal de Educação, Ciência e Tecnologia Rio Grande do Norte, fern.paciencia@gmail.com

3 Dra, Instituto Federal de Educação, Ciência e Tecnologia Rio Grande do Norte, cristina.cavalcanti@ifrn.edu.br
} 
espaço geográfico, pensar e atuar criticamente em sua realidade tendo em vista a sua transformação. Portanto, os objetivos da aula devem ficar bem claros, ao escolher um filme para a exibição.

Nesse sentido, ao trabalhar o CineCal, têm-se como objetivo maior fazer os alunos compreender uma realidade distante das suas realidades, entendendo as paisagens distantes, das suas e, visualizando tempos distantes, do seu tempo; com isso possibilita-nos avaliar como o aluno visualiza essas realidades.

Abaixo alguns exemplos do uso de filmes no CineCal:

$\checkmark$ Levar os alunos para realidades distantes de seu convívio, como no filme Diário de Motocicletas 2004, que mostra as paisagens sul-americanas, retrata as relações sociais pelo poder, entre pobres e ricos. E aproximá-los dessa realidade para facilitar a aprendizagem.

$\checkmark$ Trazer filmes que inter-relacione temas abordados nas aulas expositivas da disciplina de Geografia, como no filme Barão de Mauá 1999, que retrata um pequeno indicio da industrialização no Brasil, do século XIX, que conduz os alunos para um tempo distante dos dias de hoje.

$\checkmark$ Ao final de cada seção realizasse uma roda de debate para expor as ideias principais por trás da trama, para que os alunos enxerguem os aspectos geográficos nos filmes, assim como sanar as dúvidas que possam ter surgido durante o filme.

No entanto e, em linhas gerais, algumas situações devem ser levadas em conta na escolha dos filmes, tais como: a questão de abordar filmes que não casem com os assuntos abordados em sala de aula e a falta de interesse dos alunos por filmes maçantes, com histórias longas, "sem ação".

Após a exibição do filme, é solicitado um relatório que relacione o roteiro do filme com o tema abordado na sala de aula. No tange a avalição é preocupante que os alunos busquem cópia de sinopses e sinopses da Internet, sem a preocupação de realmente atestar os próprios conhecimentos, por vezes o resultado não reflete a opinião do aluno com o assunto abordado.

\section{Fundamentação Teórica}


Segundo Moran (1995), em seu artigo “O Vídeo na Sala de Aula” o vídeo é uma ferramenta didática que pode render bons resultados. Usando-o, ultrapassamos a barreira das aulas expositivas, tendo em vista que os alunos de hoje são muito dinâmicos e uma aula em que o professor é o centro do processo não prende a atenção do aluno. O vídeo é uma ferramenta útil para sensibilizar os alunos a refletirem sobre as questões socioeconômicas e ambientais.

Segundo os conceitos de Moran (1995), este novo recurso é capaz de transportar o aluno da sala de aula até o Egito Antigo na aula de História, ou até o Amazonas na aula de Biologia, por exemplo. Da mesma forma, será capaz de mostrar as características e peculiaridades da Depressão Sertaneja. Pretende-se usar o vídeo como conteúdo de ensino de forma direta, informando sobre o tema específico e orientando a sua interpretação. O objetivo é de levar os estudantes à uma realidade distante, sem sair da sala de aula.

\footnotetext{
Vídeo como expressão, como nova forma de comunicação, adaptada à sensibilidade principalmente das crianças e dos jovens. As crianças adoram assistir vídeo e a escola precisa incentivar o máximo possível a produção de pesquisas em vídeo pelos alunos. A produção em vídeo tem uma dimensão moderna, lúdica. Moderna, como um meio contemporâneo, novo e que integra linguagens (MORAN,1995, p 4).
}

Segundo Matta (2009), diferentemente de outros gêneros cinematográficos, as características dos filmes documentais não se fixam com rigidez, o que deriva, em parte, uma grande imprecisão em conceituá-los. As definições sobre documentários são sempre comparativas, muitas vezes advindas de seu contraste com os filmes de ficção. Os documentários mostram aspectos ou representações auditivas de uma parte do mundo histórico. Eles significam ou representam os pontos de vistas de indivíduos, grupos e instituições. Também fazem representações, elaboram argumentos ou formulam suas próprias estratégias persuasivas, visando convencer-nos a aceitar suas opiniões.

As muitas formas de expressão artísticas tentam refletir os diversos contextos de uma época, nos diz a respeito de uma sociedade, com seus medos e desejos. O cinema nos possibilita lazer e diversão, mas também acesso a informações e cenários a um baixo custo e de forma rápida. Embora de maneira superficial e muitas das vezes tendenciosa Pereira (2009). 
Dentre as atividades que desenvolvemos na sala de aula, normalmente, utilizamos os recursos audiovisuais para introduzir ou concluir uma temática. Em ambos os casos, pode-se adotar uma série de estratégias para serem desenvolvidas durante e após a apresentação. Por exemplo, o professor pode pedir para os alunos anotarem em seus cadernos a respeito de paisagens, lugares presentes, alimentação, sociedade como ela é representada no filme, documentário ou desenho que foram (ou poderão ser) desenvolvidas ao longo do ano letivo. O ideal é correlacionar com o assunto abordado pelo livro didático e não limitar aulas expositivas maçantes. (PEREIRA, 2009).

\section{Metodologia}

Este é um trabalho de caráter qualitativo, pois ainda não houve tempo para fazermos uma comparação, para o obtermos dados quantitativos; quanto aos procedimentos técnicos até aqui foram usados tipos de metodologias a Pesquisa Experimental e Pesquisa Documental.

Pesquisa Experimental, pois determinamos um objeto de estudo, que nesse caso é algo que vem da matéria ministrada através de uma aula expositiva dialogada; seleciona-se as variáveis, que aqui seria os diversos filmes para apresentá-los aos alunos e selecionasse um o que mais se aproxima da realidade e do conteúdo ministrado; este seriam capazes de influenciá-lo, define-se as formas de controle e de observação dos efeitos que a variável produz no objeto.

Para a análise dos resultados usamos Pesquisa Documental, pois esta forma valese de materiais que não receberam ainda um tratamento analítico, ou que ainda podem ser reelaborados de acordo com os objetos da pesquisa. E nos proporciona avaliar os documentos de "primeira mão", no caso os relatórios e ou os resumos, que nos permite interpretações os resultados obtidos pelos alunos.

\section{Resultados e Discussões}

Nota-se, nos últimos bimestres deste ano uma clara melhoria no entendimento dos assuntos abordados, com o auxílio dos filmes, dos alunos envolvidos no processo. Além disso, a participação dos alunos em atividades relacionadas ao projeto CineCal foi muito satisfatória, o que atesta a hipótese de que o cinema é uma ferramenta enriquecedora, tanto para a prática pedagógica da leitura quanto para a interpretação 
textual. Já pode-se afirmar o sucesso do projeto para a melhoria na aprendizagem, na disciplina de geografia, com os temas abordados. Porém, serão necessários mais um ou dois anos para termos resultados quantitativos, significativos para comparamos os dados referentes ao percentual de notas, por amostragem e de aprovação, e claro, de reprovação.

Por fim, e com a constante busca na melhoria do projeto buscaremos expandir a ideia para o CineCal começar a abranger outras disciplinas, tornando-se assim interdisciplinar por seu caráter que permite diálogo e vai além da imagem projetada.

\section{Conclusões}

Diante do relato, pode-se inferir que muitos aspectos abordados em salas de aulas pelo projeto CineCal são relevantes pela oportunidade que os alunos têm de expandir seus horizontes através do cinema, e uma ferramenta importantíssima para os professores se bem trabalhada.

Isto reforça as palavras de Moran (1995), que afirma que o cinema explora também e, basicamente, o ver, o visualizar, o ter diante de nós as situações, as pessoas, os cenários, as cores, as relações espaciais (próximo-distante, alto-baixo, direita esquerda, grande-pequeno, equilíbrio-desequilíbrio). Desenvolve um ver entrecortado com múltiplos recortes da realidade através dos planos - e muitos ritmos visuais: imagens estáticas e dinâmicas, câmera fixa ou em movimento, uma ou várias câmeras, personagens quietos ou movendo-se, imagens ao vivo, gravadas ou criadas no computador.

Professores que lecionam disciplinas ligadas diretamente a fenômenos da natureza e ao meio ambiente, se interessaram em usar em seus conteúdos filmes, e consequentemente utilizá-los para contextualizar fatos e acontecimentos, o que a testa $o$ sucesso do uso de filmes na Escola Estadual Castro Alves.

\section{Referências}

MATTA, H. Mas afinal, o que é documentário? 2009

MORAN, J.M. O Vídeo na Sala de Aula. São Paulo: Revista Comunicação \& Educação, 1995

PEREIRA, L.A.S. Os filmes, documentários e desenhos e o ensino da geografia. Porto Alegre, 2009 